\title{
Shape-forming and densification of ceramic superconductors
}

\author{
OM PRAKASH*, R M ANKLEKAR, N K KHOSLA, SUNIL \\ KUMAR, B CHAUDHURI, C A THOMAS*, A P MAGADUM*, \\ M RAMESH, B T RAO and T R RAMA MOHAN
}

Department of Metallurgical Engineering, *Materials Science Centre, Indian Institute of Technology, Powai, Bombay 400076, India.

\begin{abstract}
Processing studies on varied shape-forming and densification of bulk ceramic superconductor, $\mathrm{YBa}_{2} \mathrm{Cu}_{3} \mathrm{O}_{7-\delta}$, are reported in this paper. Polyvinyl butyral-polyethylene glycol-trichloroethylene has been found to be the best binder-plasticizer-solvent system in plastic shape-forming. The effect of initial particle morphology on final densification has been the most sensitive single parameter as compared to compaction pressure and final sintering durations at $\sim 930^{\circ} \mathrm{C}$. 1-2-3 powders of mean particle size $\sim 1.94 \mu \mathrm{m}$ have yielded sintered densities $\sim 92 \%$ T.D. albeit with lower oxygen intake $\mathrm{O}_{6 \cdot 7}$.
\end{abstract}

Keywords. Oxide superconductors; $\mathrm{YBa}_{2} \mathrm{Cu}_{3} \mathrm{O}_{7-\delta}$; shape-forming; binder-plasticizersolvent system.

\section{Introduction}

Shape-forming of superconducting ceramics has gained a lot of impetus recently due to the fact that various oxide compounds hitherto unknown have been found to exhibit superconductivity (SC) above the boiling point of liquid nitrogen. This has extended the horizon of various applications of these materials when given specific shapes and configurations (Umeda et al 1988; Enomoto et al 1989; Prakash et al 1989). The shape-forming of one class of oxide superconductors viz. $\mathrm{YBa}_{2} \mathrm{Cu}_{3} \mathrm{O}_{7-\delta}$ $(1-2-3)$ is similar to the fabrication of advanced ceramics. In the present work, some of the established shape-forming methods viz. die-pressing, extrusion and tape casting (Poeppel et al 1989) have been employed. One of the important variables which greatly influences the final properties of the material is the starting powder size-distribution and morphology. The starting powder characteristics have been found to influence greatly the sintered density, grain size and orientation. These in turn, affect the mechanical strength and critical current density $\left(J_{c}\right)$ of the SC samples. A careful process control results in improvement of $J_{c}$, the most sought after parameter.

Shape-forming of 1-2-3 powder involves selection of compatible binder-plasticizersolvent system(s) to form a plastic mass. Properties like plastic deformation capacity, rheological behaviour of the viscous 1-2-3 matrix and the binder removal characteristics prior to sintering need to be optimized in order to shape the oxidic SC with desired properties (Colo and Migliore 1989; Saunders 1989). The problem areas with batch-scale production of bulk 1-2-3 ceramic SC are: presence of residual carbon due to incomplete decomposition of $\mathrm{BaCO}_{3}$ precursor, slow oxygen kinetics and oxygen intake by the dense samples, high sensitivity to moisture and $\mathrm{CO}_{2}$ of the ambient, low $J_{c}$ and low mechanical strength (Yan et al 1988; Mitchell et al 1989; Poeppel et al 1989). In this paper we report processing studies on shape-forming and densification of bulk $1-2-3$ ceramics. 

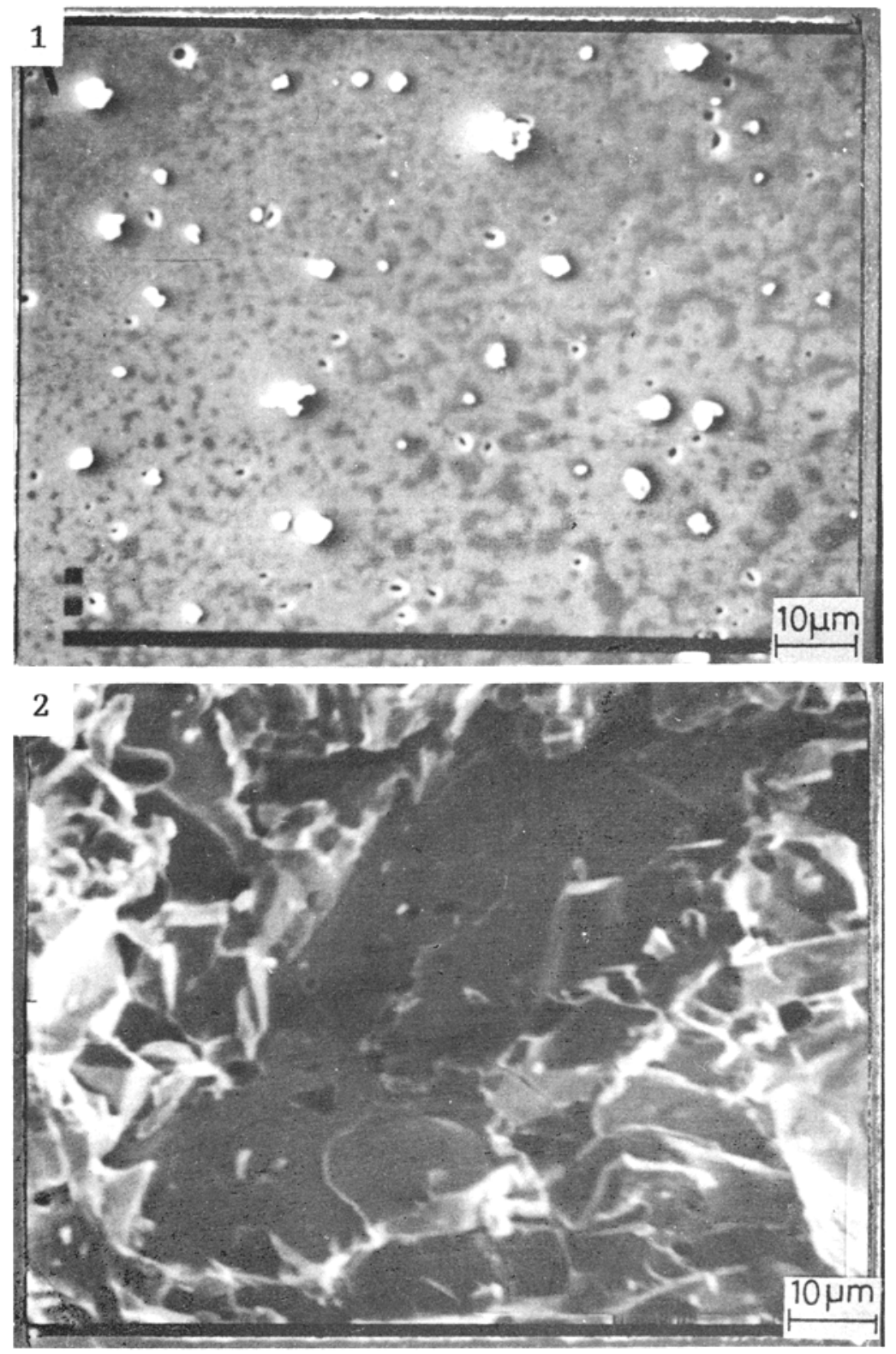

Figures 1-3. For caption, see next page. 


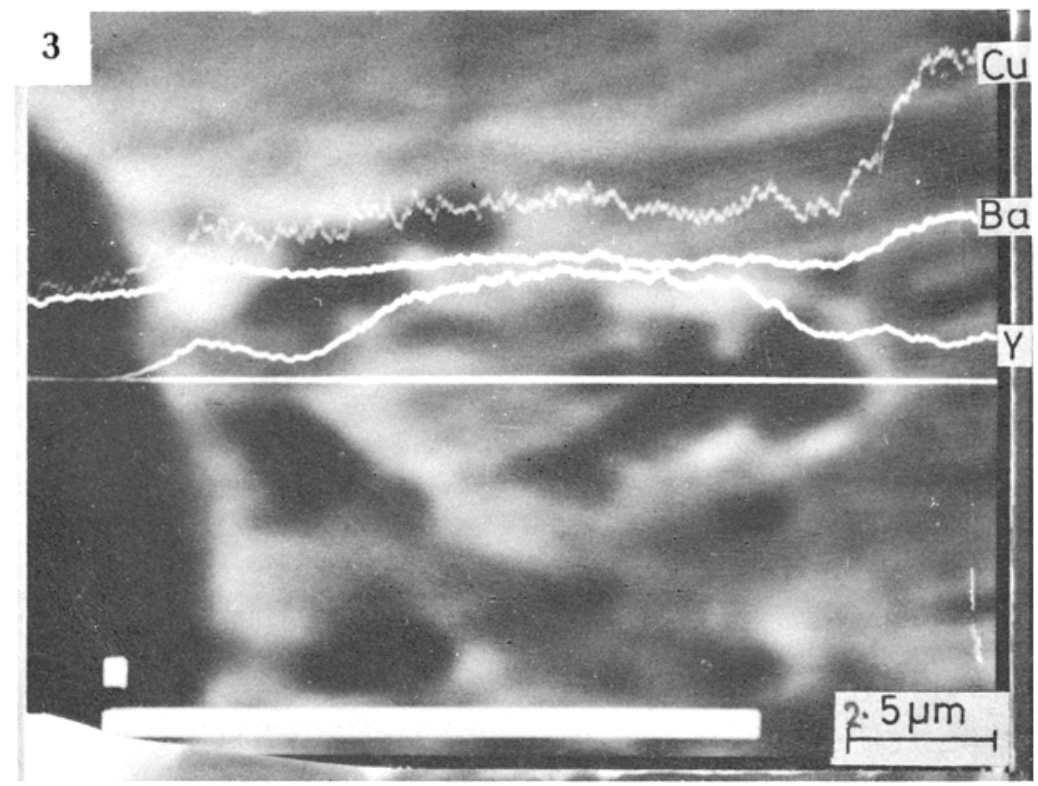

Figures 1-3. Secondary electron image of the finally sintered 1-2-3 powder. 2. Secondary electron image of the fractured surface of the 1-2-3 pellet. 3. Inverted target current image and $\mathrm{X}$-ray line scan for $\mathrm{Y}, \mathrm{Ba}$ and $\mathrm{Cu}$ cations.

\section{Experimental}

$\mathrm{YBa}_{2} \mathrm{Cu}_{3} \mathrm{O}_{7-\delta}$ powders were synthesized by solid-state reaction of $99.9 \%$ purity $\mathrm{Y}_{2} \mathrm{O}_{3}, \mathrm{BaCO}_{3}$ and $\mathrm{CuO}$ in 1:4:6 molar ratio. These powders were intimately mixed in planetary mill, compacted into pellets, presintered at $\sim 930 \mathrm{C}$ for $\sim 24 \mathrm{~h}$ in flowing oxygen and slowly cooled to room temperature. The pellets were ground to fine powder, pelletized and sintered at $-930^{\circ} \mathrm{C}$ for $24 \mathrm{~h}$ in oxygen atmosphere and slowly cooled to $500^{\circ} \mathrm{C}$ and annealed at this temperature for $36-48 \mathrm{~h}$. The pellets were ground to fine powders by hand grinding and/or ball milling.

The powders were characterized for particle-size distribution by laser technique using Galai-CIS 1. Electron probe micro-analyzer (EPMA) of CAMECA, model CAMEBAX-R was used to get particle size and shape and fractured surface images in secondary electron (SE) mode. X-ray line scans for $\mathrm{Y}, \mathrm{Ba}$ and $\mathrm{Cu}$ cations were obtained using wavelength dispersive mode. The 1-2-3 phase formation and its purity was checked using X-ray diffraction (XRD) and EPMA. The lattice oxygen concentration was estimated by iodometric titration. The alumina contamination from the grinding media was determined by XRF analysis using Philips PW 1410 spectrometer. The resistivity of different batch pellets was measured using the four-probe technique.

Samples from different mean particle size batches of 1-2-3 powders compacted at different pressures were sintered for densification studies. Some specific shapes viz. rods, substrates, toroids, rings, disks, pellets and bars were made by die compaction and $\sim 1 \mathrm{~mm}$ diameter wires few meters in length by extrusion. Polyvinyl butyral/polymethyl methacrylate-trichloroethylene/methyl ethyl ketone bindersolvent systems were tried for shape-forming. Polyethylene glycol and dioctyl phthalate were used as plasticizers along with pine oil as dispersant. The binders 


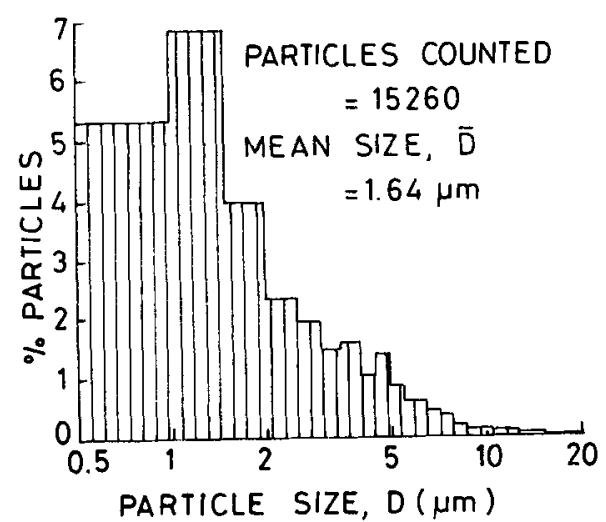

Figure 4. Particle-size distribution histogram for a $100 \mathrm{~g}$ batch of $1-2-3$ powder.

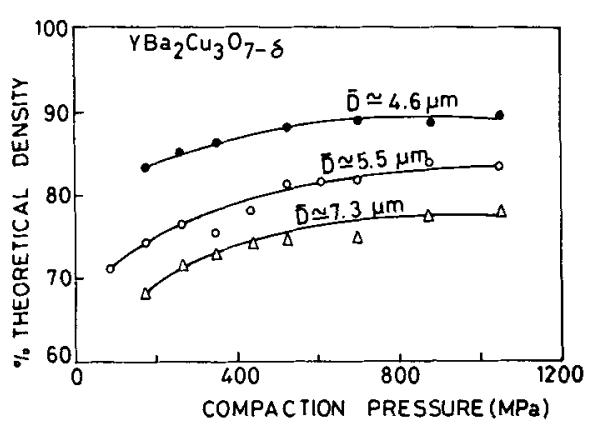

Figure 5. Effect of compaction pressure on sintered density for different mean size powders.

were burnt at a very slow rate up to $500^{\circ} \mathrm{C}$ to avoid microcracks. The residual carbon in the final sintered samples was determined using Ströhlein's Coulomat 702.

\section{Results and discussion}

Figure 1 shows SE image of the finally sintered 1-2-3 powder. The average particle size is $\sim 3.8 \mu \mathrm{m}$ as obtained by IAS. The micrograph indicates that the particles are by and large rounded and angular in shape. The sintered density of the pellets bbtained using the above batch of powders was $\sim 84 \%$ theoretical density (TD). The SE image of the fractured surface given in figure 2 shows large platelets $\sim 5-10 \mu \mathrm{m}$ oriented in different directions.

The XRD pattern of the finally sintered pellets showed only the orthorhombic 1-2-3 phase within the detection limits of the instrument. A careful EPMA analysis however showed that one out of thirteen scanned regions $(2 \mu \mathrm{m} \times 2 \mu \mathrm{m})$ did not confine to $\mathrm{Y}: \mathrm{Ba}: \mathrm{Cu}:: 1: 2: 3$ thereby implying $\sim 7 \%$ impurity phases consisting of mainly $\mathrm{BaCuO}_{2}, \mathrm{CuO}$ and $\mathrm{Y}_{2} \mathrm{BaCuO}_{5}$ (see figure 3). The lattice oxygen for different batch samples was found to range between $\sim 6.83$ and 6.95 . The alumina contamination levels were found to be $<0.1 \%$.

Figure 4 shows the particle-size distribution histogram for a $100 \mathrm{~g}$ batch powder of $\bar{D} \sim 1.64 \mu \mathrm{m}$. For a given particle-size distribution, the density of the sintered pellets increased monotonically with compaction pressure and reached a plateau at $\sim 550 \mathrm{MPa}$ (see figure 5). As the phase diagram of 1-2-3 restricts the sintering temperatures to a narrow range of $930 \pm 20^{\circ} \mathrm{C}$, the improvement in densification is predominantly controlled by $\bar{D}$ and morphology of the initial powders. The variation of sintered density as a function of particle size for all the pellets compacted at $\sim 250 \mathrm{MPa}$ is given in figure 6 . It is observed that the particle-size distribution plays an important role in densification. Sintered densities $>90 \%$ TD could be achieved using fine powders of $\bar{D}<2 \mu \mathrm{m}$.

Figure 7 shows the transition temperature for two pellets having different lattice oxygen concentrations of 6.95 and 6.70 . The $\mathrm{O}_{6.95}$ pellet (density $\sim 82 \%$ TD) showed metallic behaviour and a narrow transition width with $T_{c}(\mathrm{R}=0)$ at $\sim 92 \mathrm{~K}$ while 

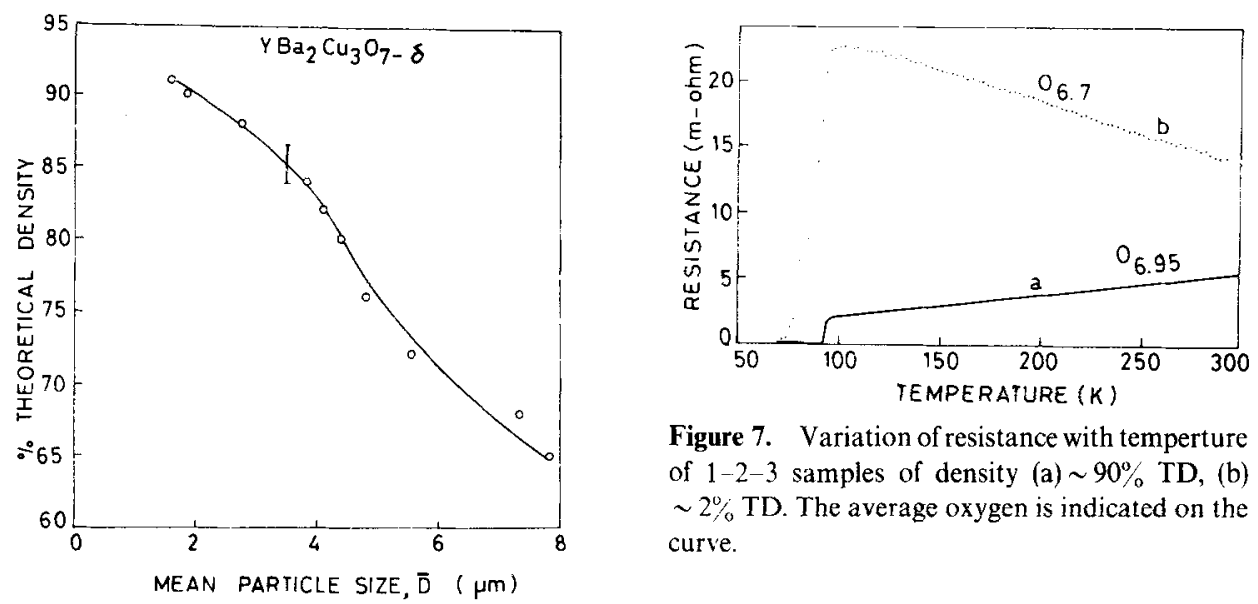

Figure 7. Variation of resistance with temperture of 1-2-3 samples of density (a) 90\% TD, (b) $\sim 2 \%$ TD. The average oxygen is indicated on the curve.

Figure 6. Variation of sintered density as a function of mean particle size for pellets compacted at $250 \mathrm{M} \mathrm{Pa}$.

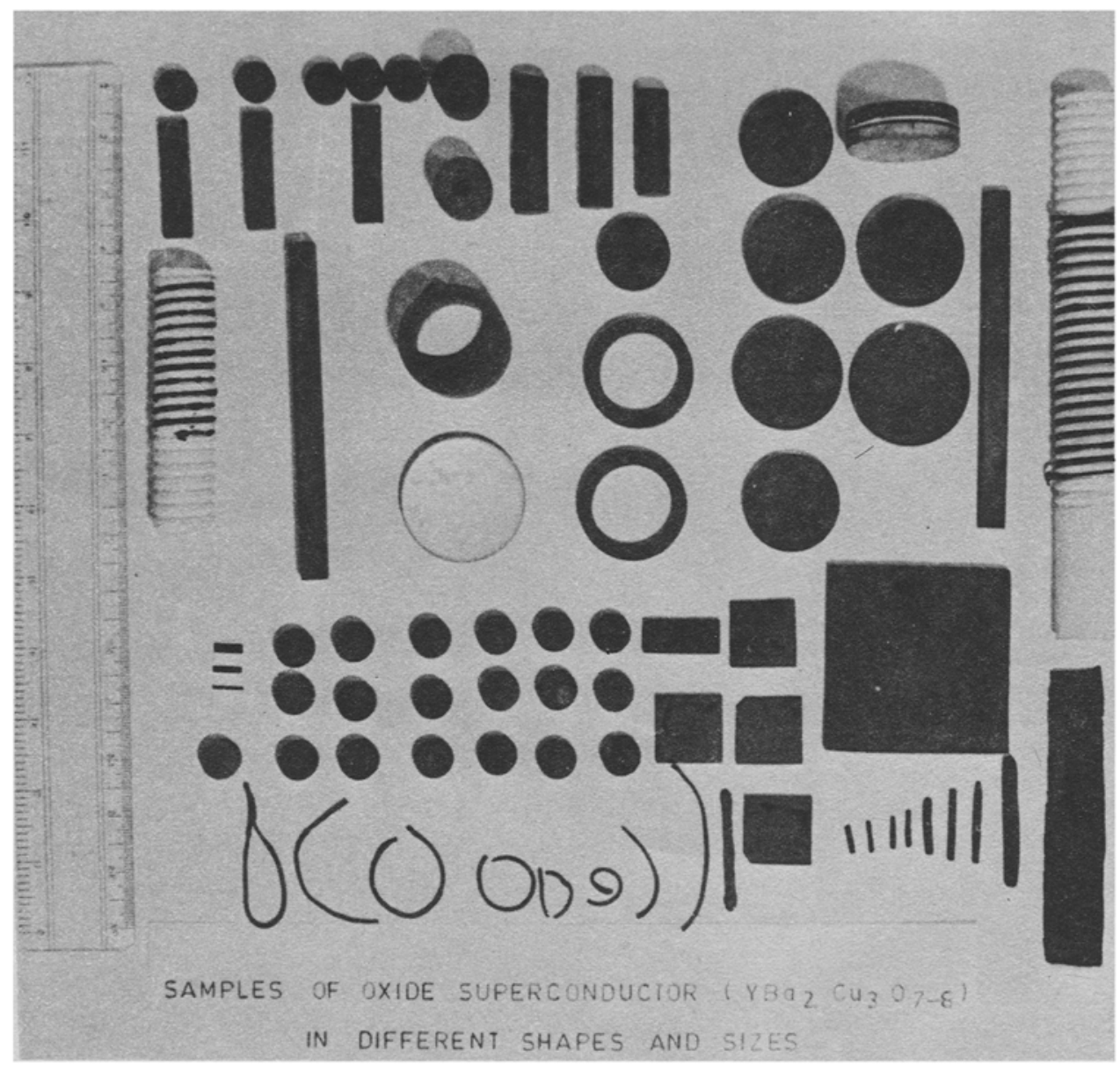

Figure 8. Various shapes fabricated of $1-2-3$ powders using different techniques. 
the $\mathrm{O}_{6.7}$ sample ( $\sim 90 \%$ TD) showed semiconductor-like behaviour indicative of mixed tetragonal and orthorhombic phases. The $T_{c}$ onset however remained unchanged at $95 \mathrm{~K}$. Strong Meissner effect at $77 \mathrm{~K}$ was observed for both types of samples.

Figure 8 shows the various shapes fabricated of 1-2-3 powders using different techniques. Polyvinyl butyral-polyethylene glycol-trichloroethylene was found to be the best binder-plasticizer-solvent system for shaping 1-2-3 powders. Some of the samples showed warping $<5 \%$ and microcracks.

\section{Conclusions}

Fine 1-2-3 powders of mean particle size $<2 \mu \mathrm{m}$ are required to achieve densities exceeding $90 \% \mathrm{TD}$. The compaction pressure beyond a certain range $(550 \mathrm{MPa})$ does not improve densification for a given particle-size distribution. EPMA has shown $\sim 7 \%$ impurity phases not detected by usual XRD in the stoichiometric composition. Polyvinyl butyral-polyethylene glycol-trichloroethylene has been the best compatible binder-plasticizer-solvent system for shape-forming. Warpage $<5 \%$ and microcracks are observed in some batch samples. The observed oxygen deficiency in dense $(\geqslant 92 \%$ TD) samples is of concern and needs further work.

\section{Acknowledgements}

This work is supported by the Programme Management Board (PMB) of the Department of Science and Technology, New Delh. The authors gratefully acknowledge the experimental facilities provided by Drs S K Bhatia, A V Narlikar, S K Agarwal, S K Sahoo and Prof. K M Pai in characterization of the SC ceramics.

\section{References}

Colo S M and Migliore L A 1989 Ceram. Ind. 13331

Enomoto R, Tamaki M, Ohno S, Fuwa M and Takei H 1989 Jpn. J. Appl. Phys. 28 L1207

Mitchell T E, Clarke D R, Embury J D and Cooper A R 1989 J. Met. 416

Poeppel R B, Dorris S E, Youngdahl C A. Singh J P, Lanagan M T, Balachandran U, Dusek J T and Goretta K C 1989 J. Met. 4111

Prakash O, Sanghavi R and Gaffoor A 1989 Proc. Int. Symp. on High $T_{c}$ superconductors, Jaipur. India (ed.) K B Garg (New Delhi: Oxford and IBH Publishing Co.) 281

Saunders Jr C S 1989 Ceram. Ind. 13335

Umeda T, Kozuka H and Sakka S 1988 Adv. Ceram. Mater. 3520

Yan M F, Ling H C, O'Bryan H M, Gallagher P K and Rhodes W W 1988 Mater. Sci. Eng. B1 119 